\title{
Ultraviolet irradiation of spray-dried porcine plasma does not affect the growth performance of nursery pigs when compared with nonirradiated bovine plasma ${ }^{1}$
}

\author{
K. M. Cottingim, * L. J. Johnston, $\uparrow$ A. M. Hilbrands, $\uparrow$ G. C. Shurson, $*$ and P. E. Urriola*2 \\ *Department of Animal Science, University of Minnesota, St. Paul 55108; \\ and $\uparrow$ West Central Research and Outreach Center, University of Minnesota, Morris 56267
}

\begin{abstract}
Ultraviolet light irradiation of spray-dried porcine plasma (SDPP) decreases the risk of disease transmission, but it may decrease the activity of bioactive components in SDPP. Therefore, the objectives of this study were to determine growth performance, morbidity, and mortality responses of nursery pigs fed UV-irradiated SDPP (UV-SDPP) compared with nonirradiated spray-dried bovine plasma (SDBP). Pigs $(n=$ $480 ; 6.09 \pm 2.4 \mathrm{~kg}$ initial BW) were blocked by initial $\mathrm{BW}$, and blocks were assigned to pens. the sex ratio was equalized within blocks and pens. Pens were randomly assigned to 1 of 5 dietary treatments ( 8 pigs/pen and 12 replicates/treatment) in 3 3-phase feeding program (phase $1=\mathrm{d} 0$ to 13 , phase $2=\mathrm{d} 14$ to 27 , and phase $3=\mathrm{d} 28$ to 55). Dietary treatments included a control diet without UV-SDPP or SDBP and diets containing 3\% UV-SDPP, $3 \%$ SDBP, $6 \%$ UV-SDPP, or 6\% SDBP during phase 1. Diets were formulated to meet or exceed nutrient requirements and contained the same concentrations of standardized ileal digestible Lys and Lys:ME ratio within phases. Pigs were provided ad libitum access to diets throughout the 55-d experiment. Dietary inclusion rates during phase 2 were reduced to $1.5 \%$ UV-SDPP, $1.5 \%$
\end{abstract}

SDBP, 3\% UV-SDPP, and 3\% SDBP, and all pigs were fed a common diet without UV-SDPP or SDBP during phase 3. Growth performance data were analyzed as a $2 \times 2$ factorial arrangement of treatments with a control within a completely randomized block design to evaluate the main effects of plasma processing (UV irradiated vs. nonirradiated) and dietary inclusion level, and block, room, and pen were random effects. In phase 1, there were no differences in $\mathrm{G}: \mathrm{F}$ among treatments, but pigs fed 6\% UV-SDPP and 6\% SDBP had greater $(P<0.01)$ $\operatorname{ADG}(0.11$ vs. $0.08 \mathrm{~kg} / \mathrm{d})$ and ADFI ( 0.17 vs. $0.15 \mathrm{~kg} / \mathrm{d})$ than pigs fed the control, 3\% SDBP, and 3\% UV-SDPP diets. After phase 1 (d13), feeding UV-SDPP or SDBP increased $(P=0.02)$ the $\mathrm{BW}$ of pigs. In phases 2 and 3 and the overall feeding period (d 0 to 55 ), there were no differences in ADG, ADFI, and G:F among dietary treatments. There was a linear decrease $(P<0.01)$ in mortality of nursery pigs as dietary inclusion rate of SDBP and UV-SDPP increased. In conclusion, feeding SDBP or UV-SDPP diets improved ADG and ADFI during the first $2 \mathrm{wk}$ after weaning due to improved feed consumption, and UV irradiation appeared to have no detrimental effects on the feeding value of SDPP.

Key words: growth performance, mortality, nursery pigs, spray-dried bovine plasma, spray-dried porcine plasma, ultraviolet light irradiation

(C) 2017 American Society of Animal Science. All rights reserved.

J. Anim. Sci. 2017.95:3120-3128 doi:10.2527/jas2017.1486

\section{INTRODUCTION}

Spray-dried porcine plasma (SDPP) and spraydried bovine plasma (SDBP) are ingredients with a high concentration of very digestible protein, and numerous studies have documented the benefits of feed-

\footnotetext{
${ }^{1}$ Financial support from APC, Inc.

${ }^{2}$ Corresponding author: urrio001@umn.edu.

Received February 18, 2017.

Accepted April 25, 2017.
}

ing diets containing SDPP to weaned pigs (Gatnau et al., 1989; Pérez-Bosque et al., 2016). Functional proteins contained in animal plasma are responsible for the beneficial effects, and spray drying is a rapid heating process necessary for conserving the biological activity of these proteins (Torrallardona, 2010). However, there is a risk of disease transmission when feeding improperly processed porcine-derived tissues to pigs, and feeding SDPP was associated with transmission of porcine epidemic diarrhea virus (PEDv) to nursery pigs (Pasick et al., 2014). This risk appears to be relatively 
low because spray drying inactivates porcine circovirus (Pujols et al., 2008, 2011; Shen et al., 2011) and porcine reproductive and respiratory syndrome virus (Polo et al., 2005). Likewise, spray drying appears to inactivate PEDv (Gerber et al., 2014; Pujols and Segalés, 2014). In fact, a recent risk analysis indicated low to negligible probability of PEDv transmission among herds of pigs consuming SDPP (Sampedro et al., 2016).

In spite of evidence suggesting low risk of virus transmission, additional procedures that may mitigate risk of virus transmission through SDPP need to be evaluated. Ultraviolet irradiation effectively inactivated porcine parvovirus in liquid bovine plasma in a pilot scale facility (Polo et al., 2015). However, no studies have evaluated the impact of UV irradiation at a commercial facility on the functional properties of SDPP. Also, there are no data on the effect of UV-irradiated SDPP (UVSDPP) on growth performance of pigs under a mild disease challenge. Therefore, the objective of this study was to compare growth performance, morbidity, and mortality of nursery pigs fed a source of commercially produced UV-SDPP with a source of SDBP that was not irradiated under unsanitary environment.

\section{MATERIALS AND METHODS}

This experiment was conducted with approval of the University of Minnesota Institutional Animal Care and Use Committee (1507-32795A).

\section{Animals and Housing}

This study was conducted in the confinement nursery facility located at the University of Minnesota West Central Research and Outreach Center in Morris, MN. Pigs were housed in a mechanically ventilated, temperature-controlled facility that was not cleaned or disinfected after the previous group of pigs occupied the nursery. We chose this unsanitary environmental model to provide a mild and nonspecific disease challenge, which has been shown to cause a $12 \%$ decrease in ADG (Zhao et al., 2007) and a 5\% decrease in ADFI after weaning (Pastorelli et al., 2012). The magnitude of this decrease in ADG and ADFI is comparable to changes observed under field conditions (Pastorelli et al., 2012).

Weaned pigs $(n=480)$ that were the offspring of Line 2 sows mated to Line 359 sires (Pig Improvement Company, Hendersonville, TN), with an initial BW of $6.09 \pm 2.4 \mathrm{~kg}$, were obtained from a commercial unit located within $40 \mathrm{~km}$ of the research site. The sow herd was negative for porcine reproductive respiratory syndrome virus. Pigs were $19 \mathrm{~d}$ of age at weaning and were vaccinated at the sow unit $2 \mathrm{~d}$ prior to weaning with $1 \mathrm{~mL}$ CircoFLEX-2 (Boehringer Ingelheim
Vetmedica Inc., St. Joseph, MO) and $1 \mathrm{~mL}$ Micoflex (Boehringer Ingelheim Vetmedica Inc.) along with oral vaccines Arko Entero Vac (K-88 Escherichia coli; ARKO Laboratories, Ltd., Jewell, IA) and Arko Edema Vac (F-18 E. coli; ARKO Laboratories, Ltd.).

Sixty nursery pens $(2.4$ by $1.2 \mathrm{~m})$ distributed in 2 similar rooms were used. Each pen was equipped with partitions constructed of vertical steel rods and plastic grate flooring and contained one 4-hole, stainless steel, dry self-feeder and 1 cup drinker. Pigs were provided ad libitum access to feed and water for $55 \mathrm{~d}$. The 2 nursery rooms were equipped with water medicators (Dosatron International, Tresses, France). If pigs required medical intervention, the date, pig identification number, pen number, amount and type of medication administered, route of administration, and the withdrawal period were recorded.

Only pigs that were vigorous, structurally sound, and healthy were selected for the experiment. Pigs were assigned to blocks based on initial BW, and blocks were randomly assigned to 1 of 60 pens. Each pen contained 8 pigs, and pen served as the experimental unit. Pens were randomly allotted to 1 of 5 treatments in a complete randomized block design. Initial BW was balanced across rooms, and the sex ratio between gilts and barrows within pens was equalized within blocks and treatments.

\section{Diets}

The SDBP and UV-SDPP used in this experiment were obtained from APC Inc. (Ankeny, IA). The UV-SDPP manufacturing lot (AP 920; lot number D512524004-8) used in this study was PCR positive (cycle time $[\mathbf{C t}]=32$ ) for PEDV, whereas the SDBP was PCR negative $(\mathrm{Ct}>40)$, at the time of manufacturing based on analysis done at the Veterinary Diagnostic Laboratory at Iowa State University (Ames, IA). The UV irradiation method used is a proprietary process but is similar to the conditions for UV irradiation of SDPP described by Polo et al. (2015) and was adapted to commercial-scale production. All diets were formulated to meet or exceed NRC (2012) requirements for pigs with $6.5 \mathrm{~kg}$ initial BW. Diets contained 3,400 ME $\mathrm{kcal} / \mathrm{kg}$ with a $5 \%$ safety margin for Lys:ME ratio and $\mathrm{P}$ and contained no antibiotics. All diets were fed in meal form in 3 phases (phase $1=\mathrm{d} 0$ to 13 , phase 2 d 14 to 27 , and phase $3=\mathrm{d} 28$ to 55 ). In phase 1 , a control diet (CON) without UV-SDPP or SDBP and 4 diets containing either 3 or $6 \%$ UV-SDPP or nonirradiated SDBP were fed (Table 1). The inclusion of soybean meal in phase 1 diets was limited to $25 \%$, and AA from UV-SDPP or SDBP were replaced using soy protein concentrate (Soycomil-P; Archer Daniels 
Table 1. Ingredient, energy, and nutrient composition of diets fed during phase 1 (d 0 to 13 after weaning; as-fed basis)

\begin{tabular}{|c|c|c|c|c|c|}
\hline \multirow[b]{2}{*}{ Item } & \multirow[b]{2}{*}{$\mathrm{CON}^{1}$} & \multicolumn{2}{|c|}{$\mathrm{SDBP}^{1}$} & \multicolumn{2}{|c|}{ UV-SDPP $^{1}$} \\
\hline & & $3 \%$ & $6 \%$ & $3 \%$ & $6 \%$ \\
\hline \multicolumn{6}{|l|}{ Ingredient composition, $\%$} \\
\hline Corn & 40.02 & 41.93 & 43.85 & 41.93 & 43.85 \\
\hline Soybean meal, $47.5 \% \mathrm{CP}$ & 25.00 & 25.00 & 25.00 & 25.00 & 25.00 \\
\hline Soy protein concentrate & 9.66 & 4.83 & - & 4.83 & - \\
\hline Spray-dried whey & 20.00 & 20.00 & 20.00 & 20.00 & 20.00 \\
\hline Spray-dried plasma & - & 3.00 & 6.00 & 3.00 & 6.00 \\
\hline Soybean oil & 1.59 & 1.62 & 1.67 & 1.62 & 1.67 \\
\hline Monocalcium phosphate, $21 \% \mathrm{P}$ & 1.34 & 1.20 & 1.05 & 1.20 & 1.05 \\
\hline Limestone & 1.10 & 1.19 & 1.28 & 1.19 & 1.28 \\
\hline Salt & 0.10 & 0.10 & 0.10 & 0.10 & 0.10 \\
\hline Vitamin and trace mineral premix ${ }^{2}$ & 0.50 & 0.50 & 0.50 & 0.50 & 0.50 \\
\hline L-Lys $\mathrm{HCl}$ & 0.37 & 0.36 & 0.35 & 0.36 & 0.35 \\
\hline DL-Met & 0.23 & 0.21 & 0.16 & 0.21 & 0.16 \\
\hline L-Thr & 0.09 & 0.07 & 0.04 & 0.07 & 0.04 \\
\hline Total & 100.00 & 100.00 & 100.00 & 100.00 & 100.00 \\
\hline \multicolumn{6}{|l|}{ Calculated nutrient composition } \\
\hline $\mathrm{ME}, \mathrm{kcal} / \mathrm{kg}$ & 3,400 & 3,400 & 3,400 & 3,400 & 3,400 \\
\hline $\mathrm{DM}, \%$ & 90.98 & 90.85 & 90.71 & 90.85 & 90.71 \\
\hline $\mathrm{CP}, \%$ & 24.34 & 23.64 & 22.94 & 23.64 & 22.94 \\
\hline Lactose, $\%$ & 14.58 & 14.58 & 14.58 & 14.58 & 14.58 \\
\hline ADF, \% & 2.90 & 2.74 & 2.58 & 2.74 & 2.58 \\
\hline $\mathrm{NDF}, \%$ & 6.48 & 6.26 & 6.05 & 6.26 & 6.05 \\
\hline $\mathrm{Ca}, \%$ & 0.89 & 0.89 & 0.89 & 0.89 & 0.89 \\
\hline $\mathrm{P}, \%$ & 0.78 & 0.76 & 0.74 & 0.76 & 0.74 \\
\hline Digestible $\mathrm{P}, 3 \%$ & 0.47 & 0.47 & 0.47 & 0.47 & 0.47 \\
\hline $\mathrm{Na}, \%$ & 0.39 & 0.35 & 0.43 & 0.35 & 0.43 \\
\hline Lys, \% & 1.70 & 1.71 & 1.71 & 1.71 & 1.71 \\
\hline Lys:ME ratio, g/Mcal & 4.56 & 4.56 & 4.56 & 4.56 & 4.56 \\
\hline SID $^{4}$ Lys, $\%$ & 1.55 & 1.55 & 1.55 & 1.55 & 1.55 \\
\hline SID Met:Lys ratio, $\%$ & 35 & 33 & 29 & 33 & 29 \\
\hline SID Met + Cys:Lys ratio, $\%$ & 57 & 57 & 57 & 57 & 57 \\
\hline SID Thr:Lys ratio, $\%$ & 59 & 59 & 59 & 59 & 59 \\
\hline SID Trp:Lys ratio, $\%$ & 17 & 17 & 18 & 17 & 18 \\
\hline \multicolumn{6}{|l|}{ Analyzed composition, $\%$} \\
\hline $\mathrm{CP}$ & 23.90 & 23.16 & 23.89 & 23.85 & 22.66 \\
\hline Lys & 1.71 & 1.63 & 1.60 & 1.66 & 1.60 \\
\hline Met & 0.52 & 0.45 & 0.45 & 0.47 & 0.41 \\
\hline Met + Cys & 0.86 & 0.87 & 0.83 & 0.84 & 0.81 \\
\hline Thr & 1.00 & 1.03 & 1.03 & 1.04 & 0.97 \\
\hline Trp & 0.33 & 0.33 & 0.34 & 0.34 & 0.34 \\
\hline
\end{tabular}

${ }^{1} \mathrm{CON}=$ control diet; SDBP $=$ spray-dried bovine plasma (not irradiated); UV-SDPP = UV-irradiated spray-dried porcine plasma. The spray-dried porcine plasma was positive to porcine epidemic diarrhea virus by PCR $($ cycle time $=32)$.

${ }^{2}$ Vitamin and trace mineral premix supplied the following nutrients per kilogram of diet: 2,200,000 IU of vitamin A as retinyl acetate, 550,000 IU of vitamin $\mathrm{D}_{3}, 17,600 \mathrm{IU}$ of vitamin $\mathrm{E}$ as DL-alpha tocopheryl acetate, $880 \mathrm{mg}$ of vitamin $\mathrm{K}$ as menadione dimethylpyrimidinol bisulfite, 1,980 $\mathrm{mg}$ of riboflavin, 11,000 $\mathrm{mg}$ of niacin, $6,600 \mathrm{mg}$ of pantothenic acid as d-calcium pantothenate, $99,000 \mathrm{mg}$ of choline as choline chloride, $11 \mathrm{mg}$ of vitamin $\mathrm{B}_{12}, 440 \mathrm{mg}$ of pyridoxine, $330 \mathrm{mg}$ of folic acid, $220 \mathrm{mg}$ of thiamine, $66 \mathrm{mg}$ of biotin, $440 \mathrm{mg}$ of iodine as ethylenediamine dihydroiodide, $59 \mathrm{mg}$ of selenium as sodium selenite, 18,040 $\mathrm{mg}$ of zinc as zinc sulfate, $11,000 \mathrm{mg}$ of iron as ferrous sulfate, 1,100 $\mathrm{mg}$ of copper as copper sulfate, and 3,520 $\mathrm{mg}$ of manganese as manganese oxide.

${ }^{3}$ Standardized total tract digestible phosphorus.

${ }^{4} \mathrm{SID}=$ standardized ileal digestible.

Midland Company, Decatur, IL) to meet the standardized ileal digestible AA requirements (Makkink et al., 1994; NRC, 2012). In phase 2, dietary inclusion rates of SDBP and UV-SDPP were reduced by $50 \%$ to provide 1.5 or $3 \%$ of each source of spray-dried plasma, and ingredient concentrations were adjusted to meet all nutrient requirements of pigs during this phase (Table 2). For phase 3, all pigs were fed a common diet without SDBP or UV-SDPP (Table 3). 
Table 2. Ingredient, energy, and nutrient composition of diets fed during phase 2 (d 14 to 27 after weaning; as-fed basis)

\begin{tabular}{|c|c|c|c|c|c|}
\hline \multirow[b]{2}{*}{ Item } & \multirow[b]{2}{*}{$\mathrm{CON}^{1}$} & \multicolumn{2}{|c|}{$\mathrm{SDBP}^{1}$} & \multicolumn{2}{|c|}{ UV-SDPP $^{1}$} \\
\hline & & $1.50 \%$ & $3.00 \%$ & $1.50 \%$ & $3.00 \%$ \\
\hline \multicolumn{6}{|l|}{ Ingredient composition, $\%$} \\
\hline Corn & 51.19 & 52.38 & 53.54 & 52.38 & 53.54 \\
\hline Soybean meal, $47.5 \% \mathrm{CP}$ & 37.00 & 37.00 & 37.00 & 37.00 & 37.00 \\
\hline Soy protein concentrate & 5.00 & 2.50 & - & 2.50 & - \\
\hline Spray-dried plasma & - & 1.50 & 3.00 & 1.50 & 3.00 \\
\hline Soybean oil & 2.79 & 2.75 & 2.72 & 2.75 & 2.72 \\
\hline Monocalcium phosphate, $21 \% \mathrm{P}$ & 1.67 & 1.60 & 1.53 & 1.60 & 1.53 \\
\hline Limestone & 1.07 & 1.12 & 1.16 & 1.12 & 1.16 \\
\hline Salt & 0.40 & 0.31 & 0.23 & 0.31 & 0.23 \\
\hline Vitamin and trace mineral premix ${ }^{2}$ & 0.50 & 0.50 & 0.50 & 0.50 & 0.50 \\
\hline L-Lys $\mathrm{HCl}$ & 0.23 & 0.22 & 0.22 & 0.22 & 0.22 \\
\hline DL-Met & 0.12 & 0.11 & 0.10 & 0.11 & 0.10 \\
\hline L-Thr & 0.03 & 0.01 & - & 0.01 & - \\
\hline Total & 100.00 & 100.00 & 100.00 & 100.00 & 100.00 \\
\hline \multicolumn{6}{|l|}{ Calculated nutrient composition } \\
\hline $\mathrm{ME}, \mathrm{kcal} / \mathrm{kg}$ & 3,400 & 3,400 & 3,400 & 3,400 & 3,400 \\
\hline $\mathrm{DM}, \%$ & 89.37 & 89.29 & 89.20 & 89.29 & 89.20 \\
\hline $\mathrm{CP}, \%$ & 25.36 & 24.98 & 24.60 & 24.98 & 24.60 \\
\hline Crude fat, $\%$ & 2.62 & 2.57 & 2.51 & 2.57 & 2.51 \\
\hline ADF, \% & 3.65 & 3.57 & 3.50 & 3.57 & 3.50 \\
\hline NDF, $\%$ & 8.11 & 8.01 & 7.92 & 8.01 & 7.92 \\
\hline $\mathrm{Ca}, \%$ & 0.84 & 0.84 & 0.84 & 0.84 & 0.84 \\
\hline $\mathrm{P}, \%$ & 0.79 & 0.78 & 0.77 & 0.78 & 0.77 \\
\hline Digestible $\mathrm{P},{ }^{3} \%$ & 0.42 & 0.42 & 0.42 & 0.42 & 0.42 \\
\hline $\mathrm{Na}, \%$ & 0.20 & 0.20 & 0.20 & 0.20 & 0.20 \\
\hline Total Lys, $\%$ & 1.61 & 1.61 & 1.61 & 1.61 & 1.61 \\
\hline Lys:ME ratio, g/Mcal & 4.26 & 4.26 & 4.26 & 4.26 & 4.26 \\
\hline $\mathrm{SID}^{4}$ Lys & 1.45 & 1.45 & 1.45 & 1.45 & 1.45 \\
\hline SID Met:Lys ratio, $\%$ & 32 & 31 & 30 & 31 & 30 \\
\hline SID Met + Cys:Lys ratio, \% & 56 & 55 & 56 & 55 & 56 \\
\hline SID Thr:Lys ratio, $\%$ & 59 & 59 & 59 & 59 & 59 \\
\hline SID Trp:Lys ratio, $\%$ & 19 & 20 & 20 & 20 & 20 \\
\hline \multicolumn{6}{|l|}{ Analyzed composition, $\%$} \\
\hline $\mathrm{CP}$ & 24.40 & 23.38 & 23.90 & 23.34 & 23.62 \\
\hline Lys & 1.56 & 1.69 & 1.59 & 1.68 & 1.64 \\
\hline Met & 0.44 & 0.44 & 0.38 & 0.41 & 0.39 \\
\hline Met + Cys & 0.77 & 0.82 & 0.73 & 0.79 & 0.75 \\
\hline Thr & 0.89 & 0.96 & 0.89 & 0.92 & 0.89 \\
\hline Trp & 0.33 & 0.32 & 0.33 & 0.32 & 0.33 \\
\hline
\end{tabular}

${ }^{1} \mathrm{CON}=$ control diet; SDBP = spray-dried bovine plasma (not irradiated); UV-SDPP = UV-irradiated spray-dried porcine plasma. The spray-dried porcine plasma was positive to porcine epidemic diarrhea virus by PCR (cycle time $=32$ ).

${ }^{2}$ Vitamin and trace mineral premix supplied the following nutrients per kilogram of diet: 2,200,000 IU of vitamin A as retinyl acetate, 550,000 IU of vitamin $\mathrm{D}_{3}, 17,600 \mathrm{IU}$ of vitamin $\mathrm{E}$ as DL-alpha tocopheryl acetate, $880 \mathrm{mg}$ of vitamin $\mathrm{K}$ as menadione dimethylpyrimidinol bisulfite, 1,980 $\mathrm{mg}$ of riboflavin, 11,000 $\mathrm{mg}$ of niacin, $6,600 \mathrm{mg}$ of pantothenic acid as d-calcium pantothenate, $99,000 \mathrm{mg}$ of choline as choline chloride, $11 \mathrm{mg}$ of vitamin $\mathrm{B}_{12}, 440 \mathrm{mg}$ of pyridoxine, $330 \mathrm{mg}$ of folic acid, $220 \mathrm{mg}$ of thiamine, $66 \mathrm{mg}$ of biotin, $440 \mathrm{mg}$ of iodine as ethylenediamine dihydroiodide, $59 \mathrm{mg}$ of selenium as sodium selenite, 18,040 $\mathrm{mg}$ of zinc as zinc sulfate, $11,000 \mathrm{mg}$ of iron as ferrous sulfate, $1,100 \mathrm{mg}$ of copper as copper sulfate, and 3,520 $\mathrm{mg}$ of manganese as manganese oxide.

${ }^{3}$ Standardized total tract digestible phosphorus.

${ }^{4} \mathrm{SID}=$ standardized ileal digestible.

\section{Husbandry, Clinical Signs, and Medications}

Pigs were observed twice daily (0800 and $1600 \mathrm{~h}$ ) for general signs of poor health. A medication protocol was established a priori to avoid bias of medication administration among dietary treatments. Individual antibiotic treatments were administered when pigs displayed signs of being lethargic or had poor locomotion or severe diarrhea. Once the threshold of $3 \%$ mortality was reached in this nonspecific disease challenge environment, pigs were placed on electrolytes (Bluelite; 
Table 3. Ingredient, energy, and nutrient composition of diets fed during phase 3 (d 28 to 55 after weaning; as-fed basis)

\begin{tabular}{|c|c|}
\hline Item & Control diet \\
\hline \multicolumn{2}{|l|}{ Ingredient composition \% } \\
\hline Corn & 65.80 \\
\hline Soybean meal, $47.5 \% \mathrm{CP}$ & 30.31 \\
\hline Monocalcium phosphate, $21 \% \mathrm{P}$ & 1.36 \\
\hline Limestone & 0.97 \\
\hline Salt & 0.44 \\
\hline Vitamin/mineral premix ${ }^{1}$ & 0.50 \\
\hline L-Lys $\mathrm{HCl}$ & 0.40 \\
\hline DL-Met & 0.11 \\
\hline L-Thr & 0.11 \\
\hline Total & 100.00 \\
\hline \multicolumn{2}{|l|}{ Calculated nutrient composition } \\
\hline $\mathrm{ME}, \mathrm{kcal} / \mathrm{kg}$ & 3,300 \\
\hline $\mathrm{DM}, \%$ & 89.65 \\
\hline $\mathrm{CP}, \%$ & 20.39 \\
\hline Crude fat, $\%$ & 3.48 \\
\hline ADF, $\%$ & 3.48 \\
\hline NDF, $\%$ & 9.01 \\
\hline $\mathrm{Ca}, \%$ & 0.72 \\
\hline $\mathrm{P}, \%$ & 0.68 \\
\hline Digestible $\mathrm{P}^{2} \%$ & 0.35 \\
\hline $\mathrm{Na}, \%$ & 0.20 \\
\hline Lys, \% & 1.40 \\
\hline Lys:ME ratio, g/Mcal & 3.85 \\
\hline SID $^{3}$ Lys & 1.27 \\
\hline SID Met:Lys ratio, $\%$ & 31 \\
\hline SID Met + Cys:Lys ratio, $\%$ & 55 \\
\hline SID Thr:Lys ratio, $\%$ & 59 \\
\hline SID Trp:Lys ratio, $\%$ & 17 \\
\hline \multicolumn{2}{|l|}{ Analyzed composition, $\%$} \\
\hline $\mathrm{CP}$ & 19.36 \\
\hline Lys & 1.41 \\
\hline Met & 0.40 \\
\hline Met + Cys & 0.77 \\
\hline Thr & 0.92 \\
\hline Trp & 0.29 \\
\hline
\end{tabular}

${ }^{1}$ Vitamin and trace mineral premix supplied the following nutrients per kilogram of diet: 2,200,000 IU of vitamin A as retinyl acetate, 550,000 IU of vitamin $\mathrm{D}_{3}, 17,600 \mathrm{IU}$ of vitamin $\mathrm{E}$ as DL-alpha tocopheryl acetate, 880 $\mathrm{mg}$ of vitamin $\mathrm{K}$ as menadione dimethylpyrimidinol bisulfite, $1,980 \mathrm{mg}$ of riboflavin, $11,000 \mathrm{mg}$ of niacin, $6,600 \mathrm{mg}$ of pantothenic acid as d-calcium pantothenate, $99,000 \mathrm{mg}$ of choline as choline chloride, $11 \mathrm{mg}$ of vitamin $\mathrm{B}_{12}, 440 \mathrm{mg}$ of pyridoxine, $330 \mathrm{mg}$ of folic acid, $220 \mathrm{mg}$ of thiamine, 66 $\mathrm{mg}$ of biotin, $440 \mathrm{mg}$ of iodine as ethylenediamine dihydroiodide, $59 \mathrm{mg}$ of selenium as sodium selenite, $18,040 \mathrm{mg}$ of zinc as zinc sulfate, $11,000 \mathrm{mg}$ of iron as ferrous sulfate, 1,100 mg of copper as copper sulfate, and 3,520 $\mathrm{mg}$ of manganese as manganese oxide.

${ }^{2}$ Standardized total tract digestible phosphorus.

${ }^{3} \mathrm{SID}=$ standardized ileal digestible.

TechMix, LLC, Stewart, MN) to reduce dehydration caused by diarrhea. If this health management practice was unsuccessful and over 3\% overall mortality was reached, pigs were then administered amoxicillin (West-
Ward Pharmaceutical Corp., Eatontown, NJ) through the drinking water using automatic water medicators.

\section{Data Collection}

Pigs were individually weighed on d 0, 6, 13, 20, 27, and 55 (the exit of the nursery). Feed disappearance from the feeder in each pen was recorded on each weigh day. These data were used to calculate ADG, ADFI, and gain efficiency (G:F). Morbidity was calculated as the number of individual pigs treated with antibiotic in each pen divided by the total number of pigs assigned to each pen within diet, where a value greater than $100 \%$ corresponds to pigs treated more than once during the duration of the study. Percentage mortality in each dietary treatment was calculated using the number of dead pigs from each pen divided by the initial number of pigs in each pen.

\section{Laboratory Analysis}

Feed samples (11 samples) were retained and frozen at $-20^{\circ} \mathrm{C}$ until nutrient analysis was conducted. Samples were submitted to the Agricultural Experiment Station Chemical Laboratories (University of Missouri, Columbia, MO) for DM, CP, crude fat, and AA analysis. Standard procedures from the AOAC International (AOAC, 2012) were followed for analysis of DM (method 930.15), crude fat (method 920.39), and CP (method 990.03). A complete AA profile (method $982.30 \mathrm{E}$, including sections $\mathrm{a}, \mathrm{b}$, and c) was performed by subsampling diets 2 different times for analysis, and the average AA concentrations of these separate AA analyses are reported (Tables 1, 2, and 3). In addition, all feed samples were analyzed for transmissible gastroenteritis virus, porcine delta corona virus, and PEDv genome at the University of Minnesota Veterinary Diagnostic Laboratory in St. Paul, MN, approximately 12 mo after diets were manufactured. The $\mathrm{Ct}$ of the PCR was used to express the concentration of virus genomic material in the samples, where $\mathrm{Ct}>40$ is considered negative and $\mathrm{Ct}<40$ is considered positive.

\section{Statistical Analysis}

Growth performance (e.g., BW, ADG, ADFI, and G:F), morbidity, and mortality data were statistically analyzed as a $2 \times 2$ factorial arrangement of treatments with a control within a complete randomized block design, with individual pen serving as the experimental unit. The GLIMMIX procedure of SAS (version 9.3; SAS Inst. Inc., Cary, NC) was used to evaluate the main effects of spray-dried plasma processing (irradiated vs. nonirradiated) and inclusion level (none, low, or high) of the spray-dried plasma in the diets, and block and 
Table 4. Effects of feeding diets containing nonirradiated spray-dried bovine plasma (SDBP) and UV-irradiated spray-dried porcine plasma (UV-SDPP) on growth performance of nursery pigs

\begin{tabular}{|c|c|c|c|c|c|c|c|c|c|}
\hline \multirow[b]{2}{*}{ Item } & \multirow[b]{2}{*}{$\mathrm{CON}^{1}$} & \multicolumn{2}{|c|}{ SDBP $^{1}$} & \multicolumn{2}{|c|}{ UV-SDPP $^{1}$} & \multirow[b]{2}{*}{$\mathrm{SE}^{2}$} & \multicolumn{3}{|c|}{$P$-value } \\
\hline & & Low & High & Low & High & & Overall & Linear & Quadratic \\
\hline Number of pens & 12 & 12 & 12 & 12 & 12 & & & & \\
\hline \multicolumn{10}{|l|}{ Phase 1 (d 0-13) } \\
\hline $\mathrm{ADG}, \mathrm{kg}$ & $0.08^{\mathrm{ab}}$ & $0.08^{\mathrm{ab}}$ & $0.11^{\mathrm{c}}$ & $0.07^{\mathrm{a}}$ & $0.11^{\mathrm{c}}$ & 0.01 & 0.01 & 0.63 & $<0.01$ \\
\hline ADFI, kg & $0.15^{b c}$ & $0.14^{\mathrm{ab}}$ & $0.16^{\mathrm{c}}$ & $0.13^{\mathrm{a}}$ & $0.17^{\mathrm{c}}$ & 0.01 & 0.01 & 0.21 & $<0.01$ \\
\hline G:F & 0.43 & 0.48 & 0.62 & 0.41 & 0.56 & 0.12 & 0.28 & 0.81 & 0.07 \\
\hline \multicolumn{10}{|c|}{ Phase 2 (d 14-27) } \\
\hline $\mathrm{ADG}, \mathrm{kg}$ & 0.48 & 0.46 & 0.47 & 0.45 & 0.46 & 0.02 & 0.30 & 0.07 & 0.57 \\
\hline ADFI, kg & 0.57 & 0.54 & 0.54 & 0.52 & 0.55 & 0.02 & 0.17 & 0.02 & 0.85 \\
\hline G:F & 0.85 & 0.85 & 0.86 & 0.85 & 0.83 & 0.01 & 0.34 & 0.69 & 0.25 \\
\hline \multicolumn{10}{|c|}{ Phase 3 (d 28-55) } \\
\hline $\mathrm{ADG}, \mathrm{kg}$ & 0.71 & 0.71 & 0.74 & 0.73 & 0.71 & 0.02 & 0.48 & 0.39 & 0.62 \\
\hline ADFI, kg & 1.24 & 1.22 & 1.24 & 1.22 & 1.23 & 0.03 & 0.91 & 0.57 & 0.75 \\
\hline G:F & 0.57 & 0.58 & 0.59 & 0.60 & 0.58 & 0.01 & 0.45 & 0.13 & 0.79 \\
\hline \multicolumn{10}{|c|}{ Overall (d 0 to 55$)$} \\
\hline $\mathrm{ADG}, \mathrm{kg}$ & 0.37 & 0.36 & 0.38 & 0.35 & 0.37 & 0.02 & 0.29 & 0.40 & 0.16 \\
\hline ADFI, kg & 0.53 & 0.52 & 0.53 & 0.51 & 0.53 & 0.02 & 0.43 & 0.14 & 0.37 \\
\hline G:F & 0.67 & 0.66 & 0.71 & 0.65 & 0.67 & 0.03 & 0.32 & 0.69 & 0.11 \\
\hline \multicolumn{10}{|l|}{ BW } \\
\hline $\mathrm{d} 0, \mathrm{~kg}$ & 6.09 & 6.09 & 6.09 & 6.09 & 6.08 & $<0.01$ & 0.86 & $\mathrm{NA}^{3}$ & NA \\
\hline $\mathrm{d} 6, \mathrm{~kg}$ & 6.22 & 6.20 & 6.38 & 6.20 & 6.32 & 0.33 & 0.21 & 0.72 & 0.13 \\
\hline $\mathrm{d} \mathrm{13,} \mathrm{kg}$ & 7.28 & 7.22 & 7.64 & 7.08 & 7.59 & 0.40 & 0.02 & 0.16 & 0.09 \\
\hline $\mathrm{d} 20, \mathrm{~kg}$ & 10.18 & 9.75 & 10.21 & 9.53 & 9.99 & 0.49 & 0.06 & 0.60 & 0.85 \\
\hline $\mathrm{d} 27, \mathrm{~kg}$ & 14.30 & 13.83 & 14.25 & 13.56 & 13.99 & 0.65 & 0.11 & 0.77 & 0.56 \\
\hline d $55, \mathrm{~kg}$ & 34.55 & 33.65 & 34.86 & 33.97 & 34.05 & 1.06 & 0.36 & 0.52 & 0.76 \\
\hline \multicolumn{10}{|c|}{$\begin{array}{l}{ }^{\mathrm{a}-\mathrm{c}} \text { Means of } 12 \text { replicates with different superscripts differ at }(P>0.05) \text { using Tukey's adjustment of SAS (SAS Inst. Inc., Cary, NC) to determine the } \\
\text { least squares means. There was no linear or quadratic effect }(P>0.05) \text {. }\end{array}$} \\
\hline $\begin{array}{l}{ }^{1} \mathrm{CON}=\text { contr } \\
\text { of } \mathrm{CON}+\mathrm{UV}-\mathrm{SI} \\
\text { or spray-dried po }\end{array}$ & $\begin{array}{l}\text { t corn an } \\
\text { Low = in } \\
\text { plasma a }\end{array}$ & $\begin{array}{l}\text { bean mea } \\
\text { on of SDB } \\
\text { in phase } 1\end{array}$ & $\begin{array}{l}\text { SDBP } \\
\text { spray-dri } \\
\text { and } 3 \%\end{array}$ & $\begin{array}{l}\text { nt consis } \\
\text { cine plasn } \\
\text { e } 2 \text { diet. }\end{array}$ & $\begin{array}{l}\text { the } \mathrm{CON} \\
3 \% \text { in } \mathrm{ph} \\
\text { gs were } \mathrm{f}\end{array}$ & $\begin{array}{l}\text { BP (not } \\
\text { diet and } \\
\text { same di }\end{array}$ & $\begin{array}{l}\text { ted) and th } \\
\text { in phase } 2 \\
\text { ing phase? }\end{array}$ & $\begin{array}{l}-\mathrm{SDPP} t \\
\text { High }=\mathrm{i}\end{array}$ & $\begin{array}{l}\text { nent consisted } \\
\text { sion of SDBP }\end{array}$ \\
\hline${ }^{2} \mathrm{~A}$ total of 480 & ( 8 pigs $\mathrm{p}$ & and $12 \mathrm{p}$ & er treatn & th an av & nitial BV & $.09 \mathrm{~kg}$ & sed in the & & \\
\hline
\end{tabular}

room were random effects. However, after analysis, there were no significant interactions with room or pen, resulting in block as the main random effect. Repeated measures over time were used to account for the effect of multiple weigh days. The statement for Poisson distribution was used for morbidity and mortality data. Linear and quadratic orthogonal polynomial effects were tested with the CONTRAST option of SAS to evaluate differences among diets containing different levels of nonUV-irradiated vs. UV-irradiated spray-dried plasma and using the $\mathrm{CON}$ as $0 \%$ inclusion for both types of plasma. Data were analyzed using the UNIVARIATE procedure of SAS to evaluate normality of model residuals. When appropriate, means were separated using Tukey's adjustment and reported as least squares means. No pen data were removed from the data set as outliers due to the high variance among treatments. Effects were considered significant at $P<0.05$, whereas trends were reported when $0.05 \leq P \leq 0.10$.

\section{RESULTS AND DISCUSSION}

\section{Growth Performance}

During phase 1, ADG of pigs fed $6 \%$ SDBP and $6 \%$ UV-SDPP was greater $(P<0.05)$ than that of pigs fed $3 \%$ SDBP or 3\% UV-SDPP, but ADG of pigs fed $3 \%$ SDBP and 3\% UV-SDPP was not different from that of pigs fed the CON (Table 4). The improvement in ADG appeared to be a result of greater ADFI $(P$ $<0.05$ ) of pigs fed $6 \%$ SDBP or $6 \%$ UV-SDPP compared with pigs fed 3\% SDBP or 3\% UV-SDPP during the first $2 \mathrm{wk}$ after weaning. Greater ADFI and ADG resulted in heavier $(P=0.02)$ pigs at $\mathrm{d} 13$ when pigs were fed diets containing $6 \%$ SDBP or UV-SDPP. There were no differences in G:F among dietary treatments. A meta-analysis of 5 experiments suggests a $43 \%$ increase in ADG of pigs fed SDBP compared with pigs fed the control diets during the first week after weaning (Torrallardona, 2010). This magnitude of 
Table 5. Effects of feeding diets with spray-dried bovine plasma (SDBP) and UV-irradiated spray-dried porcine plasma (UV-SDPP) on morbidity and pen final weight of nursery pigs

\begin{tabular}{lcccccc}
\hline \hline & & \multicolumn{3}{c}{ SDBP $^{1}$} & & UV-SDPP $^{1}$ \\
\cline { 2 - 6 } Item & $\mathrm{CON}^{1}$ & Low & High & Low & High & $P$-value \\
\hline Overall treatments administered, ${ }^{2} \%$ & 109 & 107 & 101 & 114 & 110 & 0.28 \\
Final pen weight, $\mathrm{kg}$ & 96.5 & 95.2 & 102.0 & 96.7 & 100.4 & 0.20 \\
\hline
\end{tabular}

${ }^{1} \mathrm{CON}=$ control diet (corn and soybean meal). The SDBP treatment consisted of the CON + SDBP (not irradiated) and the UV-SDPP treatment consisted of CON + UV-SDPP. Low = inclusion of SDBP or spray-dried porcine plasma at 3\% in phase 1 diet and 1.5\% in phase 2 diet; High = inclusion of SDBP or spray-dried porcine plasma at $6 \%$ in phase 1 diet and 3\% in phase 2 diet. All pigs were fed the same diet during phase 3 .

${ }^{2}$ Percent of pens that received injections. A value greater than $100 \%$ indicates that pigs within these pens were injected more than once.

improvement in ADG is similar to the $38 \%$ observed in the current experiment for pigs fed $6 \%$ SDBP or $6 \%$ UV-SDPP diets compared with pigs fed the CON.

During phase 1, there were no differences in ADG, ADFI, or G:F between SDBP and UV-SDPP fed at either a 3 or $6 \%$ inclusion rate. This observation is consistent with earlier observations (Russell, 1994; Gatnau et al., 1995; Russell and Weaver, 1996) and results from a summary of multiple experiments (van Dijk et al., 2001), in which feeding bovine-derived or porcine-derived spray-dried plasma improved ADG compared with a control diet but no differences in ADG were observed among sources of plasma. Results from recent experiments conducted under environmental stress conditions have also shown no differences in ADG of pigs fed $6 \%$ bovine- or porcinederived spray-dried plasma (Crenshaw et al., 2015).

Despite greater ADG and ADFI in the first week after weaning for pigs fed $6 \%$ UV-SDPP or $6 \%$ SDBP diets compared with pigs fed the $\mathrm{CON}$, pigs fed the $\mathrm{CON}$ were able to compensate by attaining similar BW at the end of the experiment compared with pigs fed $6 \%$ spraydried plasma phase 1 diets. After the initial 2 wk of this feeding period, the benefits of diets containing $6 \%$ spraydried plasma diminished in our study. This transient effect was also observed by Pierce et al. (2005). However, it may be possible that despite similar BW at the end of the 55-d nursery period, pigs fed diets with $6 \%$ SDPP or $6 \%$ SDBP early in life are better prepared to survive subsequent disease challenges (Boyer et al., 2015).

\section{Morbidity and Mortality}

Pigs in the current study were weaned at $19 \mathrm{~d}$ of age and subjected to additional environmental and health challenges that were achieved by using unsanitary housing facilities (Pastorelli et al., 2012). Under these conditions, along with feeding nonmedicated diets, $80 \%$ of pigs fed the $\mathrm{CON}$ required injectable medications (expressed as morbidity) within the first $6 \mathrm{~d}$ after weaning (data not shown). On d 11, all pigs were provided electrolytes in their drinking water (Bluelite; TechMix, LLC) and were treated with amoxicillin (West-Ward Pharmaceutical
Corp.) in their drinking water on $\mathrm{d} 20,27$, and 33. At the end of the experiment, $109 \%$ of pigs were treated with injectable antibiotics in the CON, indicating that some pigs were treated more than once. However, there were no differences in morbidity (overall percentage of pigs treated) among dietary treatments when evaluating individual injectable medications (Table 5). The most significant effect of feeding UV-SDPP or SDBP diets was observed by decreased mortality rather than a decrease in morbidity. There was a linear $(P<0.01)$ decrease in mortality of pigs fed increasing dietary levels of UVSDPP or SDBP (Fig. 1). Furthermore, there were multiple causes of morbidity and mortality for the 36 pigs that died or were removed from the experiment. Necropsies confirmed that 3 pigs died from signs of colibacillosis (E. coli), 6 pigs died from signs of Streptococcus suis infection, 19 pigs died due to nonspecific signs of poor health, and 8 pigs were humanely euthanized due to animal welfare concerns. The greatest health challenge was observed during the first week after weaning, when 21 pigs were removed ( 8 from the CON, 5 from 3\% SDBP, 4 from 3\% UV-SDPP, 3 from 6\% SDBP, and 1 from $6 \%$ UV-SDPP). Nine pigs were removed during phase 2 (2 from the CON, 2 from 3\% SDBP, 2 from 3\% UV-SDPP, 1 from $6 \%$ SDBP, and 2 from $6 \%$ UV-SDPP), and 6 pigs were removed during phase 3 ( 1 from the CON, 2 from $3 \%$ SDBP, 0 from $3 \%$ UV-SDPP, 0 from $6 \%$ SDBP, and 3 from $6 \%$ UV-SDPP). Although dead pigs were not tested for presence of PEDv by PCR, no clinical signs of PEDv infection were observed during this study and none of the gross lesions during on-farm necropsies indicated presence of PEDv.

The reductions in mortality of pigs fed spray-dried animal plasma suggest that the current disease challenge model was effective and that feeding spraydried animal plasma provides benefits in addition to improvements in ADFI and ADG. A common observation is that pigs raised in institutional research facilities (with low pig and pathogen density) have less disease challenge than pigs in commercial facilities (Coffey and Cromwell, 1995). Therefore, feeding trials testing interventions to mitigate negative impact of disease challenge are not suitable to make inferences 


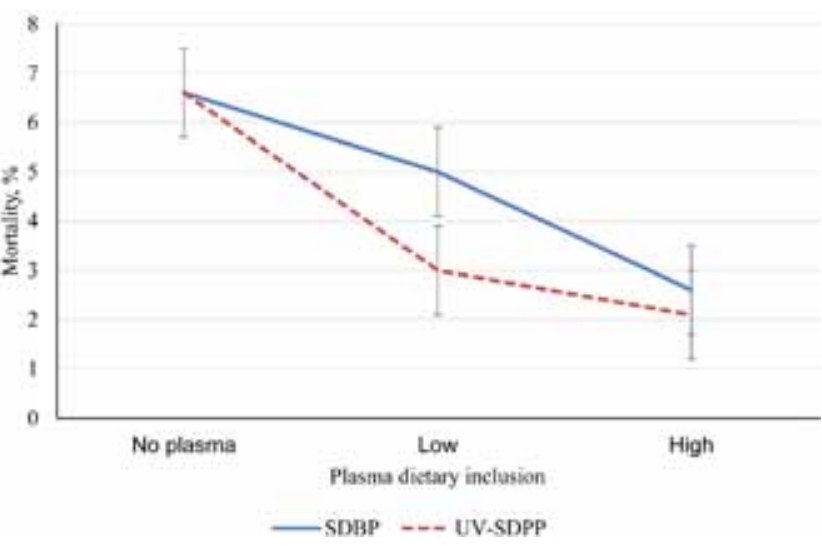

Figure 1. Effects of feeding diets containing UV-irradiated spraydried porcine plasma (UV-SDPP) or nonirradiated spray-dried bovine plasma (SDBP) at low diet inclusion (3\% in phase 1 and $1.5 \%$ in phase 2 ) and high diet inclusion (6\% in phase 1 and $3 \%$ in phase 2$)$ on mortality of pigs during the nursery period. Linear decrease for SDBP diets $(P<0.01$, $\left.R^{2}=0.89\right)$ and linear decrease for UV-SDPP diets $\left(P<0.01, R^{2}=0.99\right)$; error bars indicate SEM 0.9.

on the effectiveness of the intervention in growth of pigs in commercial facilities. However, our observations suggest that the unsanitary housing conditions used in our research facilities was effective, potentially generating a greater environmental microbial load, which appeared to provide a disease challenge more than that observed on commercial farms in the U.S. pork industry because the mortality rate was greater than the 5\% reported for most farms (NPB, 2015). Therefore, it is possible to infer that pigs fed under commercial conditions would also respond in magnitude similar to the improvements in growth performance and reductions in mortality that were observed in this experiment from feeding UV-SDPP or SDBP diets (Torrallardona, 2010; Pujols et al., 2016).

The results of the current experiment demonstrate that UV-SDPP was effective in sustaining ADFI and ADG of nursery pigs in the first week after weaning in a magnitude comparable to the literature and suggests that commercial UV irradiation of porcine plasma is not detrimental to the functional proteins contained in this high-protein ingredient similar to other proteins (Choudhary and Bandla, 2012; Christen et al., 2013). Also, the fact that growth of pigs fed UV-SDPP was similar to that of pigs fed SDBP suggests that there are no detrimental effects of feeding pigs diets or feed ingredients that were UV irradiated and that UV irradiation is a process useful to decrease pathogens in spraydried plasma. This is consistent with other studies that demonstrated that feeding $\gamma$-irradiated complete diets is not detrimental to growth performance of nursery pigs (DeRouchey et al., 2001, 2003a,b; Keegan et al., 2003). It is worth mentioning that UV irradiation inactivates the virus but it does not destroy the genomic material. The manufacturing lot of UV-SDPP used in the feed for this study contained PEDV genome confirmed by a PCR $(\mathrm{Ct}=32)$. Likewise, samples of phase 1 diets containing the UV-SDPP (stored at $-20^{\circ} \mathrm{C}$ and analyzed 1 $\mathrm{yr}$ after production) had detectable PEDv genome ( $>40$ in the CON, $>40$ in 3\% SDBP, 35 in $3 \%$ UV-SDPP, $>40$ in $6 \% \mathrm{SDBP}$, and 36 in 6\% UV-SDPP). The increase in $\mathrm{Ct}$ values between the ingredient and final diets may be due to the dilution of the virus genome in the final feed after blending and to genome degradation during storage conditions $\left(12 \mathrm{mo}\right.$ at $\left.-20^{\circ} \mathrm{C}\right)$. These observations suggest that UV irradiation does not render PEDv genomic material undetectable but confirms that genomic material in SDPP was not infectious and indicates a need for developing more accurate and sensitive diagnostic methods to detect PEDv and other viruses in feed ingredients to determine their relative risk of transmission via this route (Sampedro et al., 2016).

In conclusion, the addition of $6 \%$ spray-dried plasma (bovine or porcine) in phase 1 diets improves growth performance of nursery pigs, especially when pigs are under stressful situations such as a nonspecific disease challenge. The benefits are observed not only on improvement in growth early in the nursery period but also on decrease in mortality. Porcine plasma that was UV irradiated at a commercial facility was as effective as nonirradiated bovine plasma in improving feed intake of nursery pigs during the first week after weaning. Therefore, UV irradiation on a commercial scale does not appear to negatively affect the nutritional or functional properties of spray-dried porcine plasma.

\section{LITERATURE CITED}

AOAC. 2012. Official methods of analysis of AOAC International. 19th ed. AOAC Intl., Gaithersburg, MD.

Boyer, P., S. D'Costa, L. Edwards, M. Milloway, E. Susick, L. Borst, S. Thakur, J. Campbell, J. Crenshaw, and J. Polo. 2015. Early-life dietary spray-dried plasma influences immunological and intestinal injury responses to later-life Salmonella typhimurium challenge. Br. J. Nutr. 113:783-793. doi:10.1017/ S000711451400422X

Choudhary, R., and S. Bandla. 2012. Ultraviolet pasteurization for food industry. Int. J. Food Sci. Nutr. Eng. 2:12-15. doi:10.5923/j. food.20120201.03

Christen, L., C. T. Lai, B. Hartmann, P. E. Hartmann, and D. T. Geddes. 2013. The effect of UV-C pasteurization on bacteriostatic properties and immunological proteins of donor human milk. PLoS One 8:e85867. doi:10.1371/journal.pone.0085867

Coffey, R., and G. Cromwell. 1995. The impact of environment and antimicrobial agents on the growth response of early-weaned pigs to spray-dried porcine plasma. J. Anim. Sci. 73:2532-2539.

Crenshaw, J. D., J. M. Campbell, and J. Polo. 2015. Comparison of spray dried bovine plasma versus spray dried porcine plasma in diets for weaned pigs. J. Anim. Sci. 93(Suppl. 2):312(abstr.) 
DeRouchey, J., M. Tokach, J. Nelssen, R. Goodband, S. Dritz, J. Woodworth, C. Hastad, and B. Goodband. 2001. Comparison of irradiated feed and food grade spray-dried animal plasma on nursery pig performance. In: Kansas State University Swine Day 2001, Manhattan, KS. Report of Progress 880. Kansas State Univ. Agric. Exp. Stn. Coop. Ext. Serv., Manhattan, KS. p. 10-16.

DeRouchey, J., M. Tokach, J. Nelssen, R. Goodband, S. Dritz, J. Woodworth, B. James, and D. Real. 2003a. Effect of irradiation of individual feed ingredients and the complete diet on nursery pig performance. J. Anim. Sci. 81:1799-1805.

DeRouchey, J., M. Tokach, J. Nelssen, R. Goodband, S. Dritz, J. Woodworth, M. Webster, and B. James. 2003b. Effects of blood meal $\mathrm{pH}$ and irradiation on nursery pig performance. J. Anim. Sci. 81:1013-1022.

Gatnau, R., C. Cain, M. Drew, and D. Zimmerman. 1995. Mode of action of spray-dried porcine plasma in weanling pigs. J. Anim. Sci. 73(Suppl. 1):82. (Abstr.)

Gatnau, R., P. Paul, and D. Zimmerman. 1989. Spray dried porcine plasma as a source of immunoglobulins for newborn piglets. J. Anim. Sci. 67(Suppl. 1):244. (Abstr.)

Gerber, P. F., C.-T. Xiao, Q. Chen, J. Zhang, P. G. Halbur, and T. Opriessnig. 2014. The spray-drying process is sufficient to inactivate infectious porcine epidemic diarrhea virus in plasma. Vet. Microbiol. 174:86-92. doi:10.1016/j.vetmic.2014.09.008

Keegan, T., C. Hasted, J. M. DeRouchey, J. L. Nelssen, M. D. Tokach, R. D. Goodband, and S. S. Dritz. 2003. Comparison of antimicrobial alternatives in irradiated diets for nursery pigs. Kansas State University. Agricultural Experiment Station and Cooperative Extension Service. Swine Day 106-110, Manhattan, KS. Report of Progress 880. Kansas State Univ. Agric. Exp. Stn. Coop. Ext. Serv. Manhattan, KS. p. 106-110.

Makkink, C. A., G. P. Negulescu, Q. Guixin, and M. W. Verstegen. 1994. Effect of dietary protein source on feed intake, growth, pancreatic enzyme activities and jejunal morphology in newly-weaned piglets. Br. J. Nutr. 72:353-368. doi:10.1079/ BJN19940039

National Pork Board (NPB). 2015. 2009-2014 Analysis of US pork industry productivity. http://www.pork.org/wp-content/uploads/2010/04/pork-industry-productivity-analysis-2015-summary.pdf. (Accessed 10 January 2016.)

NRC. 2012. Nutrient requirements of swine. Natl. Acad. Press, Washington, DC.

Pasick, J., Y. Berhane, D. Ojkic, G. Maxie, C. Embury-Hyatt, K. Swekla, K. Handel, J. Fairles, and S. Alexandersen. 2014. Investigation into the role of potentially contaminated feed as a source of the first-detected outbreaks of porcine epidemic diarrhea in Canada. Transbound. Emerg. Dis. 61:397-410. doi:10.1111/tbed.12269

Pastorelli, H., N. Le Floc'h, E. Merlot, M. Meunier-Salaün, J. Van Milgen, and L. Montagne. 2012. Sanitary housing conditions modify the performance and behavioral response of weaned pigs to feed and housing-related stressors. Animal 6:1811-1820. doi:10.1017/S1751731112001231

Pérez-Bosque, A., J. Polo, and D. Torrallardona. 2016. Spray dried plasma as an alternative to antibiotics in piglet feeds, mode of action and biosafety. Porcine Health Manage. 2:16. doi:10.1186/ s40813-016-0034-1

Pierce, J., G. Cromwell, M. Lindemann, L. Russell, and E. Weaver. 2005. Effects of spray-dried animal plasma and immunoglobulins on performance of early weaned pigs. J. Anim. Sci. 83:2876-2885.
Polo, J., J. Quigley, L. Russell, J. Campbell, J. Pujols, and P. Lukert. 2005. Efficacy of spray-drying to reduce infectivity of pseudorabies and porcine reproductive and respiratory syndrome (PRRS) viruses and seroconversion in pigs fed diets containing spraydried animal plasma. J. Anim. Sci. 83:1933-1938.

Polo, J., C. Rodríguez, J. Ródenas, L. E. Russell, J. M. Campbell, J. D. Crenshaw, D. Torrallardona, and J. Pujols. 2015. Ultraviolet light (UV) inactivation of porcine parvovirus in liquid plasma and effect of UV irradiated spray dried porcine plasma on performance of weaned pigs. PLoS One 10:e0133008. doi:10.1371/ journal.pone. 0133008

Pujols, J., S. López-Soria, J. Segalés, M. Fort, M. Sibila, R. Rosell, D. Solanes, L. Russell, J. Campbell, J. Crenshaw, E. Weaver, and J. Polo. 2008. Lack of transmission of porcine circovirus type 2 to weanling pigs by feeding them spray-dried porcine plasma. Vet. Rec. 163:536-538. doi:10.1136/vr.163.18.536

Pujols, J., C. Lorca-Oró, I. Díaz, L. E. Russell, J. M. Campbell, J. D. Crenshaw, J. Polo, E. Mateu, and J. Segalés. 2011. Commercial spray-dried porcine plasma does not transmit porcine circovirus type 2 in weaned pigs challenged with porcine reproductive and respiratory syndrome virus. Vet. J. 190:e16-e20. doi:10.1016/j. tvj1.2011.02.021

Pujols, J., and J. Segalés. 2014. Survivability of porcine epidemic diarrhea virus (PEDV) in bovine plasma submitted to spray drying processing and held at different time by temperature storage conditions. Vet. Microbiol. 174:427-432. doi:10.1016/j. vetmic.2014.10.021

Pujols, J., J. Segalés, J. Polo, C. Rodríguez, J. Campbell, and J. Crenshaw. 2016. Influence of spray dried porcine plasma in starter diets associated with a conventional vaccination program on wean to finish performance. Porcine Health Manage. 2:4-15. doi:10.1186/s40813-016-0021-6

Russell, L. 1994. Effect of plasma source and processing method on postweaning performance of pigs. J. Anim. Sci. 72(Suppl. 1):136. (Abstr.)

Russell, L., and E. Weaver. 1996. Strategic application of blood proteins in feeding strategies for early weaned pigs and calves. In: Proc. Am. Assoc. Swine Pract. Am. Assoc. Swine Vet., Perry, IA. p. 37-45.

Sampedro, F., T. Snider, I. Bueno, J. Bergeron, P. E. Urriola, and P. Davies. 2016. Risk assessment of feed ingredients of porcine origin as vehicles for transmission of porcine epidemic diarrhea virus (PEDV). http://research.pork.org/FileLibrary/ ResearchDocuments/14-164-DAVIES-UofMN.pdf (Accessed January 10, 2016.)

Shen, H. G., S. Schalk, P. G. Halbur, J. M. Campbell, L. E. Russell, and T. Opriessnig. 2011. Commercially produced spray-dried porcine plasma contains increased concentrations of porcine circovirus type 2 DNA but does not transmit porcine circovirus type 2 when fed to naïve pigs. J. Anim. Sci. 89:1930-1938. doi:10.2527/jas.2010-3502

Torrallardona, D. 2010. Spray dried animal plasma as an alternative to antibiotics in weanling pigs - A review. Asian-Australas. J. Anim. Sci. 23:131-148.

van Dijk, A., H. Everts, M. Nabuurs, R. Margry, and A. Beynen. 2001. Growth performance of weanling pigs fed spray-dried animal plasma: A review. Livest. Prod. Sci. 68:263-274. doi:10.1016/ S0301-6226(00)00229-3

Zhao, J., A. Harper, M. Estienne, K. Webb, A. McElroy, and D. Denbow. 2007. Growth performance and intestinal morphology responses in early weaned pigs to supplementation of antibioticfree diets with an organic copper complex and spray-dried plasma protein in sanitary and non-sanitary environments. J. Anim. Sci. 85:1302-1310. 